\title{
Assessment of Infant and Young Child Feeding Practices of Caregiver's in Jashore City, Bangladesh
}

\author{
Afroza Sharmin', Niaz Mahmud1 (), Md. Jannatul Ferdaus', M. N. A. Siddiqui', \\ Md. Sidur Rahman ${ }^{3}$, Mahbubur Alam Dewan1, Tanvir Ahmad1* \\ ${ }^{1}$ Department of Nutrition and Food Technology, Jashore University of Science \& Technology, Jashore, Bangladesh \\ ${ }^{2}$ BIRTAN, Regional Station, Jhenaidah, Bangladesh \\ ${ }^{3}$ Nutrition, Department of Women Affairs, Ministry of Women and Children Affairs, Government of the Peoples Republic of \\ Bangladesh, Bangladesh \\ Email: ^fmtanvir_nft@just.edu.bd, ^fmtanvir@gmail.com
}

How to cite this paper: Sharmin, A., Mahmud, N., Ferdaus, Md.J., Siddiqui, M.N.A., Rahman, Md.S., Dewan, M.A. and Ahmad, T. (2020) Assessment of Infant and Young Child Feeding Practices of Caregiver's in Jashore City, Bangladesh. Food and Nutrition Sciences, 11, 194-206.

https://doi.org/10.4236/fns.2020.113015

Received: January 16, 2020

Accepted: March 14, 2020

Published: March 17, 2020

Copyright $\odot 2020$ by author(s) and Scientific Research Publishing Inc. This work is licensed under the Creative Commons Attribution International License (CC BY 4.0).

http://creativecommons.org/licenses/by/4.0/

\begin{abstract}
Since infant and young child feeding practices play an important role in ameliorating childhood nutrition, an exploratory and descriptive study has thus been conducted employing a previously developed questionnaire at Ad-din shisu Hospital, Jashore, Bangladesh to obtain better insights about the breastfeeding and complementary feeding practices among infant and young child feeding caregivers. Out of 260 babies, 54\% were female and $46 \%$ were male. Nearly all caregivers were found having the idea that breast milk is the best food for newborn babies. Around $81.9 \%$ of caregivers think that breast milk contains all the nutrients the baby needs to flourish, but in case of protection from disease, only $18.1 \%$ of caregivers think that it protects the baby from certain diseases. Around $46.9 \%$ mothers practiced early initiation of breastfeeding and they offered breast milk to their newborn right away (within one hour) after delivery, 53.5\% lactating mothers had proper knowledge about breastfeeding methods, 39.6\% mothers never practiced burping after breastfeeding, $66.4 \%$ mothers had normal delivery, $33.6 \%$ mothers had caesarian section, $99 \%$ mothers offered colostrums to their babies and only $1 \%$ of them didn't give the colostrums. Besides, $88.8 \%$ continued breastfeeding up to 24 months or more along with $83.8 \%$ caregivers starting complementary feeding from six months, $55.4 \%$ caregivers said baby's immune system is less developed, so they get attacked by infection easily and $44.6 \%$ caregivers said "their tummies are vulnerable to infection", and $48.8 \%$ of the caregivers followed the type of hygiene required. Our findings revealed information on the knowledge, attitude, and practices of the caregiver's towards breastfeeding and complementary feeding.
\end{abstract}


Keywords

Breastfeeding, Complementary Feeding, Infant and Young Child, Caregivers

\section{Introduction}

Breastfeeding; the divine act of providing milk to a newborn or infant from the mother's breast is a mode of providing ideal food for the infants to grow and flourish [1] [2]. Breast milk is sterile, easily-digested, and non-allergenic responsible for transmitting maternal antibodies to the newborn or infant that protect against many ailments, infections and illnesses [3] [4]. Researches transpired [4] [5] that breastfeeding is the most advantageous and complete method of infant feeding occupying almost all the necessary nutrients, growth factors, and immunological components in terms of the requirement for an infant for proper development. Internationally, breastfeeding is promoted as the preferred method of feeding infants up to 6 months of age and continuing up to 2 years of age [6]. Although the health benefits of breastfeeding are accredited extensively, opinions and recommendations are divided on the optimal duration of exclusive breastfeeding. Exclusive Breastfeeding is as the World Health Organization (WHO) says exclusive breastfeeding is when feeding an infant is only limited with breast milk without any additional supplementation or food components such as water, juices or solids [7]. Global monitoring studies found that approximately $38 \%$ of infants fewer than 6 months of age in the developing countries are exclusively breastfed, whereas in Bangladesh the exclusive breastfeeding rate is $43 \%$ up to 6 months [8] [9]. The duration of breastfeeding is an important factor to extend exclusive breastfeeding [7]. Unfortunately, the breastfeeding initiation and duration rate was quite low in both developed and developing countries and particularly in Bangladesh [8]. In Bangladesh, more than two-thirds of all infant deaths occurred due to diarrheal diseases and respiratory tract infections [10]. The prevalence of diarrhea and acute respiratory infection in infants aged between 0 - 3 months was significantly associated with a lack of exclusive breastfeeding [11]. Thus, breastfeeding is indispensable to reduce neonatal and infant mortality and morbidity rates. Breastfeeding is also a cost-effective approach for children's health improvement and decreases the load of childhood diseases [12]. Children born in a health facility or those whose births were attended by a health professional had a lower likelihood of breastfeeding within one hour of birth than those born at home [13]. The tradition of giving pre-lacteal feeds is widely practiced with $62 \%$ of newborns receiving such feeds [13] [14]. The most common early feeds consist of sugar or glucose water (42\%), milk other than breast milk (36\%), and honey (33\%) [13] [14], thus the proportion of exclusively breastfed infants drops sharply from $52 \%$ at $2-3$ months to $23 \%$ at 4 - 5 months [13] [14]. Besides, delayed initiation of breastfeeding is common in Bangladesh. Studies conducted in Bangladesh reported that only 60 
percent of the infants were given colostrums [15] [16]. An earlier report showed that 69 percent of the women initiated breastfeeding on the third day [15] [16]. There are several factors influencing breastfeeding practices among caregivers. These include mother's motifs and beliefs about insufficient breast milk, support from the family members, financial insufficiency, household workload and apathy towards feeding [17]. Alongside, Support from a baby's father by active participation in decision making about breastfeeding has a powerful effect on the initiation and duration of breastfeeding [17]. The father's role includes child caring, doing household work, ensuring the mother's care during breastfeeding or when the mother feels tired [18]. Mothers from rich families stopped breastfeeding earlier than mothers of poorer families due to their ability to buy powdered milk and other baby formulas [5] [7]. A study in Bangladesh revealed that the women who lived in rural areas were less likely to stop breastfeeding than the mothers who lived in urban areas [6]. Another study mentioned that women whose partners were highly educated and had professional or executive occupations were more likely to breastfeed their babies than women whose partners had lower educational levels and lower-status occupations [19]. Breastfeeding in Bangladesh is almost "universal" while several other aspects are still problematic including delayed initiation of breastfeeding, use of pre lacteal feeds, and use of supplements from an early age [14]. In Bangladesh, almost 97\% of mothers breastfeed their children for a while [6] [13] [20] A study was conducted in Dhaka, Bangladesh that looked at the effects of community-based peer counseling on exclusive breastfeeding practices showed a significant increase in women who breastfeed exclusively [21]. Seventy percent of women in the intervention group who participated in community-based peer counseling were giving exclusive breastfeeding, compared to only $6 \%$ in the control group [21]. Recent data showed that only 38 percent of children aged 2 - 3 months were exclusively breastfed and 23 percent of children were given complementary foods before the 6 months [11]. In Bangladesh, the rate of exclusive breastfeeding practice is about 43 percent [10]. Complementary foods are introduced to an infant at a time when breast milk alone is not sufficient to meet the energy and nutrient requirements of the growing infant [10] [16]. Therefore the aim of introducing complementary foods is to serve as a complement to breast milk to meet the infant's requirements [16]. Implying that, the energy intake from breast milk decreases as the infant age increases; therefore the deficit in the energy of 200 $\mathrm{kcal} /$ day, $300 \mathrm{kcal} /$ day and $550 \mathrm{kcal} /$ day at age $6-8,9-11$ and $12-23$ months respectively are to be met from complementary food [10] [16]. The WHO \& UNICEF have recommended that complementary feeding starts at 6 months, with continued breastfeeding for up to two years. The complementary feeding period is the most challenging when it comes to infant feeding as it has been widely recognized that optimal complementary feeding does not depend on only what is fed but also on how, when, where and by whom the child is fed [10] [16]. 


\section{Methodology}

\subsection{Study Area}

The study was conducted at Ad-din shisu Hospital in Jashore, Bangladesh during a period of 5 months starting from July 2018 to November 2018.

\subsection{Study Design}

An exploratory and descriptive cross-sectional was conducted to obtain better insights about breastfeeding and complementary feeding practices among infant and young child feeding caregivers.

\subsection{Study Population}

The study population was 260 babies from 0 to 24 months of age who came to Ad-din shisu Hospital for regular checkups and treatment. The babies were from various villages of Jashore district, Bangladesh.

\subsection{Data Analysis}

Data we reanalyzed using the Statistical Package for the Social Science (SPSS) (version 16.0) and descriptive analysis was employed to calculate frequency and percentage. Frequency tables and charts were used to present the summarized data.

\section{Results and Discussion}

The study was conducted to assess the situation of breastfeeding and complementary feeding practices of children of $0-24$ months at Ad-din shisu Hospital in Jashore, Bangladesh. Among 260 babies, 54\% (140 babies) were female and $46 \%$ (120 babies) were male. The age group of the babies categorized in months. Socio-demographic characteristics of respondent babies and caregivers are summarized in (Table 1). About $15 \%$ of babies were between 0 - 6 months, $38 \%$ were between 7 - 12 months, $27 \%$ were between $13-18$ months and $20 \%$ were between 19 - 24 months of age (Table 1). The majority of the babies had normal birth weight $63.9 \%(2.5-3.9 \mathrm{~kg})$ but the percentage of low birth weight $25.3 \%$ $(1.5-2.4 \mathrm{~kg})$ was not too low. There was a very low birth weight $(0-1.4 \mathrm{~kg})$ baby and $0.7 \%(>4 \mathrm{~kg})$ overweight baby. Studies reported that rates of low birth weight among Bangladeshi children are among the highest in the world with $30 \%-40 \%$ of babies weighing less than $2500 \mathrm{~g}$ at birth [5] [6]. It has been thought that improved nutrition for mothers during pregnancy in an utmost necessity to reduce these skyrocketed rates [14].

The caregiver's knowledge about food during pregnancy and for baby's data is summarized in (Table 2). All mothers think that breast milk is the best food for newborn babies among 260 respondents. About $81.9 \%$ of mothers think that breast milk contains all the nutrients the baby needs but only $18.1 \%$ of mothers think it protects the baby from certain diseases. On the other hand, for the early initiation of breastfeeding, only $46.9 \%$ of mothers practice early initiation of 
Table 1. Socio-demographic characteristics of respondent babies and caregivers.

\begin{tabular}{|c|c|c|}
\hline \multicolumn{3}{|c|}{ Respondent Babies } \\
\hline Characteristics & Frequency & Percentage (\%) \\
\hline \multicolumn{3}{|l|}{ Gender } \\
\hline Male & 140 & 53.85 \\
\hline Female & 120 & 46.15 \\
\hline \multicolumn{3}{|l|}{ Birth weight } \\
\hline Very low $(0-1.5 \mathrm{~kg})$ & 5 & 1.92 \\
\hline Low $(1.6-2.4 \mathrm{~kg})$ & 66 & 25.38 \\
\hline Normal (2.5 - $3.9 \mathrm{~kg})$ & 166 & 63.85 \\
\hline Over Weight (>4 kg) & 7 & 2.70 \\
\hline \multicolumn{3}{|l|}{ Age (months) } \\
\hline $0-6$ & 39 & 15 \\
\hline $7-12$ & 99 & 38 \\
\hline $13-18$ & 70 & 27 \\
\hline $19-23$ & 52 & 20 \\
\hline \multicolumn{3}{|l|}{ Birth Defect } \\
\hline No & 252 & 96.93 \\
\hline Heart & 1 & .38 \\
\hline Stomach & 6 & 2.31 \\
\hline Musculoskeletal & 1 & .38 \\
\hline \multicolumn{3}{|l|}{ Physical disabilities } \\
\hline Yes & 5 & 1.92 \\
\hline No & 255 & 98.08 \\
\hline \multicolumn{3}{|c|}{ Complications of CF before 6 months } \\
\hline Fever & 32 & 12.31 \\
\hline Digestion problem & 81 & 31.15 \\
\hline No complication & 147 & 56.54 \\
\hline \multicolumn{3}{|c|}{ Caregiver's } \\
\hline \multicolumn{3}{|c|}{ Educational status of Father } \\
\hline Illiterate & 15 & 5.77 \\
\hline Primary & 100 & 38.46 \\
\hline SSC & 51 & 19.62 \\
\hline HSC & 52 & 20 \\
\hline Graduate & 27 & 10.38 \\
\hline Postgraduate & 15 & 5.77 \\
\hline \multicolumn{3}{|c|}{ Educational status of Mother } \\
\hline Illiterate & 11 & 4.23 \\
\hline Primary & 133 & 51.15 \\
\hline SSC & 69 & 26.54 \\
\hline HSC & 31 & 11.92 \\
\hline
\end{tabular}




\section{Continued}

\begin{tabular}{ccc}
\hline Graduate & 10 & 3.85 \\
Post graduate & 6 & 2.31 \\
Father's monthly income (BDT) & & \\
$5000-10,000$ & 77 & 29.62 \\
$10,000-15,000$ & 83 & 31.92 \\
$15,000-20,000$ & 65 & 25 \\
$20,000-30,000$ & 35 & 13.46 \\
Breastfeeding complications & & \\
Yes & 2 & 0.77 \\
No & 258 & 90.23 \\
Breastfeeding failure & & 0 \\
Yes & 0 & 100 \\
No & 260 & \\
\hline
\end{tabular}

Table 2. Caregiver's knowledge about food during pregnancy and for babies.

\begin{tabular}{|c|c|c|}
\hline Categories & Frequency & Percentage (\%) \\
\hline \multicolumn{3}{|l|}{ Avoided foods during pregnancy } \\
\hline 7 up, medicine & 1 & 0.38 \\
\hline Coconut & 1 & 0.38 \\
\hline Palm, Pineapple & 1 & 0.38 \\
\hline Papaya & 44 & 16.93 \\
\hline Papaya, pineapple & 36 & 13.85 \\
\hline Pineapple & 11 & 4.23 \\
\hline Don’t know & 166 & 63.85 \\
\hline \multicolumn{3}{|l|}{ Advantages of breastfeeding } \\
\hline Contains all the nutrients & 213 & 81.92 \\
\hline Protects baby from diseases & 47 & 18.08 \\
\hline \multicolumn{3}{|l|}{ Best food for newborn baby } \\
\hline Breast milk & 260 & 100 \\
\hline \multicolumn{3}{|l|}{ Early initiation of breastfeeding } \\
\hline Within 30minutes to 1 hour & 122 & 46.92 \\
\hline Any time in the first day of life & 57 & 21.92 \\
\hline After 1 day or more & 77 & 29.62 \\
\hline I don't know & 4 & 1.54 \\
\hline \multicolumn{3}{|l|}{ Colostrum contains antibodies } \\
\hline Yes & 237 & 91.16 \\
\hline No & 14 & 5.38 \\
\hline Don't know & 9 & 3.46 \\
\hline
\end{tabular}




\section{Continued}

Exclusive breastfeeding

Yes 234

Meaning of EBF

Don't know

Breast milk and infant formula

Breast milk and clean water

Breast milk alone

Breast milk is adequate for 6 months

Yes
No
Don't know

Breastfeeding is beneficial for mother

Yes

No

Breastfeeding method

Know and maintain

Didn't know

Know about complementary feeding

Yes

No

About restricted food before 1 year

Yes

No

257

About restricted food

Salt
Honey
Sugar

51

102

23

Raw or partly cooked eggs

Raw or partly cooked fish

Nuts

Importance of hygiene in $\mathrm{CF}$

Baby's immune system is less developed

144

Their tummies are vulnerable to infection
55.38

7.31

96.15

3.46

.39

90.77

53.46

46.54

0

8.85

15

10.76

6.54

4.62 
breastfeeding within 1 hour of delivery and 53.1\% mothers didn't practice early initiation of breastfeeding. Among them, 35\% of mothers had a normal delivery and $65 \%$ of mothers had a caesarian section. About $99 \%$ of mothers were offered colostrums and only $1 \%$ didn't give colostrums. Pre lacteal feeding rate was found $13 \%$. There were some specific reasons of pre-lacteal feeding. About $52.9 \%$ offered pre-lacteal food because breast milk did not flow, $23.5 \%$ because it was their tradition and $23.5 \%$ because the baby was hungry (Figure 1). About $65.4 \%$ of respondents were practicing exclusive breastfeeding and $34.6 \%$ didn't practice exclusive breastfeeding. It shows that $88.8 \%$ of respondents were continued breastfeeding up to 2 years and $11.2 \%$ didn't continue. Different surveys are done by the Bangladesh Demographic and Health Survey, United Nations Children's Fund (UNICEF), and Bangladesh Breastfeeding Foundation (BBF) showed a rate of exclusive breastfeeding to be around 32\% - 52\% [22] [23] [24], [25] [26]. In Bangladesh, many programs and projects have been promoting breastfeeding for many years and fortunately, nationally initiation of breastfeeding within one hour of birth, feeding colostrums and exclusive breastfeeding is now increasing day by day [25] [26].

This study also found complementary feeding information of babies. About $83.8 \%$ of respondents had started complementary feeding at 6 months and $16.2 \%$ didn't start at 6 months. There are some complications of starting complementary feeding before 6 months. About 12.5\% of babies were suffered from fever, $31.25 \%$ of babies were suffered digestion problems and $56.25 \%$ didn't suffer any complication. There are some reasons for giving breastfeeding along with complementary feeding. About $18.1 \%$ of mothers said its nutritious, $39.2 \%$ mothers said it's needed, $15 \%$ mothers said it's for satisfaction, $10.4 \%$ mothers said baby is willing, 3.1\% mothers said it's healthy and 3.5\% mothers said it's essential [Figure 2]. The caregiver's attitude about the food of babies is summarized in (Table 3). Only $1.2 \%$ of respondents know about restricted foods before 1 year of age and $98.8 \%$ respondent didn't know about restricted foods before 1 year of age.19.6\% caregivers were known about salt, 39.1\% caregiver's were known about honey, $8.7 \%$ caregiver's were known about sugar, 15.2\% caregiver's were. known about raw or partly cooked eggs, $10.87 \%$ caregiver's were known about

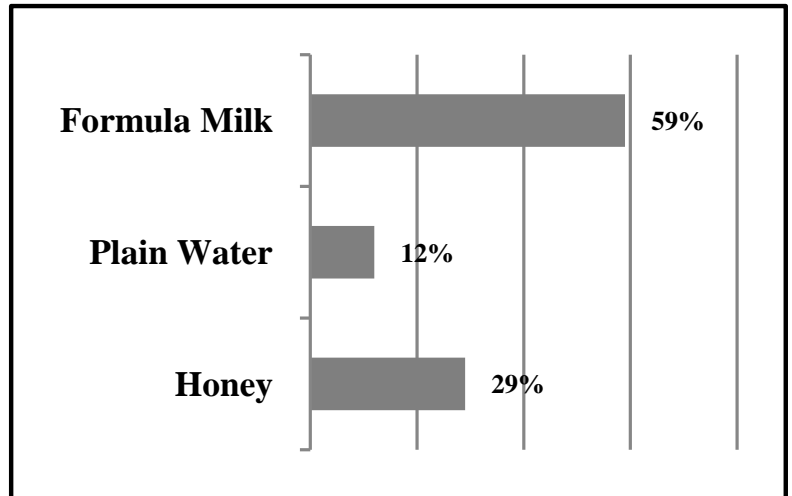

Figure 1. Pre-lacteal feeding of babies. 


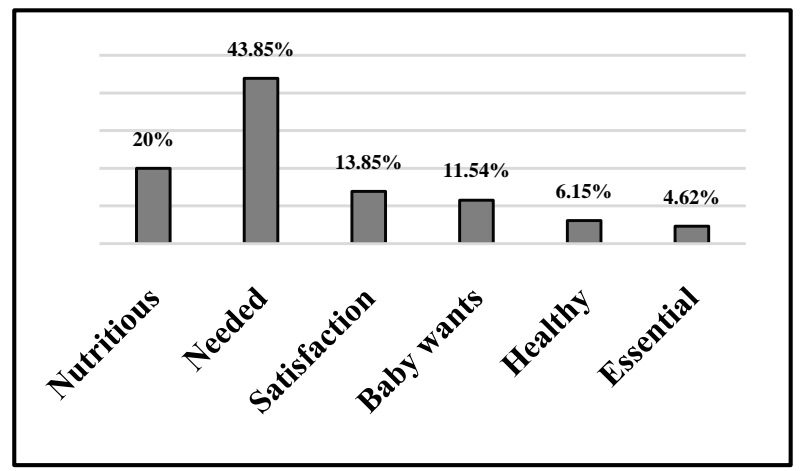

Figure 2. Reason of giving breast feeding along with complementary Feeding.

Table 3. Caregiver's attitude about the food of babies and practice of restricted food during pregnancy.

\begin{tabular}{|c|c|c|}
\hline Categories & Frequency & Percentage \\
\hline \multicolumn{3}{|l|}{ Breastfeeding up to 2 years } \\
\hline Yes & 231 & 88.85 \\
\hline No & 29 & 11.15 \\
\hline \multicolumn{3}{|l|}{ Pre-lacteal feeding } \\
\hline Yes & 34 & 13.08 \\
\hline No & 226 & 86.92 \\
\hline \multicolumn{3}{|c|}{ Breastfeeding is beneficial for mother } \\
\hline Yes & 236 & 90.77 \\
\hline No & 24 & 9.23 \\
\hline \multicolumn{3}{|c|}{ Starting Age of complementary feeding } \\
\hline 5 months & 8 & 3 \\
\hline 6 months & 252 & 97 \\
\hline \multicolumn{3}{|c|}{ Giving restricted food before 1 year } \\
\hline Yes & 3 & 1.15 \\
\hline No & 257 & 98.85 \\
\hline \multicolumn{3}{|l|}{ Not maintaining restricted food } \\
\hline Raw or partly cooked eggs & 44 & 16.92 \\
\hline Raw or partly cooked meats & 41 & 15.77 \\
\hline Raw milk & 36 & 13.85 \\
\hline Liver & 48 & 18.46 \\
\hline Caffeine & 45 & 17.31 \\
\hline Raw or partly cooked fish & 46 & 17.69 \\
\hline
\end{tabular}

raw or partly cooked fish and 6.5\% caregivers were known about nuts should be avoided before 1 year of age (Table 3 ).

The practice of caregivers is summarized in (Table 4). There was some importance to practice hygiene in complementary feeding. About $55.4 \%$ of respondents think "Baby's immune system is less developed, so they attack by 
Table 4. Practice of caregiver.

\begin{tabular}{|c|c|c|}
\hline Categories & Frequency & Percentage \\
\hline \multicolumn{3}{|l|}{ Food storage } \\
\hline Don't reheat foods & 5 & 1.92 \\
\hline Store food in the fridge & 15 & 5.77 \\
\hline Don't use baby's left foot & 240 & 92.31 \\
\hline \multicolumn{3}{|l|}{ Exclusive breastfeeding } \\
\hline Yes & 170 & 65.38 \\
\hline No & 90 & 34.62 \\
\hline \multicolumn{3}{|l|}{ Start CF at 6 months } \\
\hline Yes & 218 & 83.85 \\
\hline No & 42 & 16.15 \\
\hline \multicolumn{3}{|l|}{ Times of feeding } \\
\hline$<6-8$ times & 111 & 42.69 \\
\hline$=6-8$ times & 95 & 36.54 \\
\hline$>6-8$ times & 54 & 20.77 \\
\hline \multicolumn{3}{|l|}{ Burping after breastfeeding } \\
\hline Yes & 157 & 60.38 \\
\hline No & 103 & 39.62 \\
\hline \multicolumn{3}{|l|}{ Times of giving CF per day } \\
\hline 2 times & 92 & 35.38 \\
\hline 3 times & 114 & 43.85 \\
\hline 4 times & 25 & 9.62 \\
\hline 6 times & 29 & 11.15 \\
\hline \multicolumn{3}{|c|}{ Give breastfeeding along with $\mathrm{CF}$} \\
\hline Yes & 250 & 96.15 \\
\hline No & 10 & 3.85 \\
\hline
\end{tabular}

infection easily' and $44.6 \%$ of respondents think 'their tummies are vulnerable to infection". Wash hands before preparing meals for the baby were maintained by $48.8 \%$ caregivers, $1.5 \%$ caregivers have washed the floor, kitchen area with hot, soapy water and $40.8 \%$ caregivers have maintained hygiene when baby eat himself/herself wash his hand before eating. $46.9 \%$ of caregivers maintain early initiation of breastfeeding, $65.4 \%$ caregivers practice exclusive breastfeeding, $88.8 \%$ caregivers continue breastfeeding up to 24 months or more and $83.8 \%$ caregivers' started complementary feeding from 6 months (Table 4). So it can be concluded that the rate of early initiation of breastfeeding is very low but the other rules are maintained approximately. IYCF rules are not maintained fully though its rate of maintenance is higher than before. 


\section{Conclusion}

The present finding uncovered information on the knowledge, attitude, and practices of the caregiver's towards breastfeeding and complementary feeding. Adequate nutrition during infancy and early childhood is essential to ensure the growth, health, and development of children to their full potential. It has been recognized that breastfeeding is beneficial for both the mother and child, as breast milk is considered as the best source of nutrition for an infant. This study revealed that early initiation of breastfeeding is very important for the baby. From the findings of this study, it can be concluded that the IYCF rules are not fully maintained especially the early initiation of breastfeeding. Most of the caregivers are not conscious about adding extra salt in the infant's diet which could potentially harm the immature kidneys of the baby. A large part of the caregivers are not informed that partially cooked egg can cause typhoid fever of her child. Mothers have to be more conscious and educated. The government should implement more awareness campaigns about breastfeeding and complementary feeding. Health facilities can play a vital role in this concern. Family members also have to be more aware and careful about the baby and mother. Therefore, sustain education is recommended to the mothers, their families, and communities to improve knowledge about breastfeeding and complementary feeding to enhance the health and nutrition outcomes of mothers and their babies.

\section{Ethical approval}

Not required.

\section{Funding}

This research is not supported by any grant or funding resources.

\section{Acknowledgements}

We would like to express our gratitude to Tanvir Ahmad, Assistant professor, Department of Nutrition and Food Technology, Jashore University of Science and Technology for his generous support in this research investigation.

\section{Conflicts of Interest}

The authors declare no conflicts of interest regarding the publication of this paper.

\section{References}

[1] Black, R.E., Allen, L.H., Bhutta, Z.A., et al. (2008) Maternal and Child Undernutrition: Global and Regional Exposures and Health Consequences. The Lancet, 371, 243-260. https://doi.org/10.1016/S0140-6736(07)61690-0

[2] Davanzo, R., Bua, J. and Travan, L. (2018) Human Milk and Formulas for Neonatal Nutrition. In: Neonatology: A Practical Approach to Neonatal Diseases, Springer, New York, 557-586. https://doi.org/10.1007/978-3-319-29489-6 185 
[3] Leung, A.K.C. and Sauve, R.S. (2005) Breast Is Best for Babies. Journal of the National Medical Association, 97, 1010.

[4] Sinusas, K. and Amy, G. (2001) Initial Management of Breastfeeding. American Family Physician, 64, 981-988.

[5] Giashuddin, M.S. and Mohammad, K. (2004) Duration of Breast-Feeding in Bangladesh. Indian Journal of Medical Research, 119, 267-272.

[6] Giashuddin, M.S., Kabir, M., Rahman, A. and Hannan, M.A. (2003) Exclusive Breastfeeding and Nutritional Status in Bangladesh. The Indian Journal of Pediatrics, 70, 471-475. https://doi.org/10.1007/BF02723136

[7] Kakute, P.N., Ngum, J., Mitchell, P., Kroll, K.A., Forgwei, G.W., Ngwang, L.K. and Meyer, D.J. (2005) Cultural Barriers to Exclusive Breastfeeding by Mothers in a Rural Area of Cameroon, Africa. Journal of Midwifery \& Women's Health, 50, 324-328. https://doi.org/10.1016/j.jmwh.2005.01.005

[8] Galler, J.R., Harrison, R.H., Ramsey, F., Chawla, S. and Taylor, J. (2006) Postpartum Feeding Attitudes, Maternal Depression, and Breastfeeding in Barbados. Infant Behavior and Development, 29, 189-203. https://doi.org/10.1016/j.infbeh.2005.10.005

[9] Quinn, V., Guyon, A. and Ramiandrazafy, C. (2004) Promoting Breastfeeding in Madagascar: A Streamlined Approach to Expand to Two New Regions. Linkages Project, USAID.

[10] UNICEF (2008) The State of the World's Children 2009: Maternal and Newborn Health. Volume 9. UNICEF.

[11] Seema, M., Ampon, R., Webb, K., Almqvist, C., Kemp, A.S., Hector, D., Marks, G.B. and CAPS Team (2007) The Association between Infant Feeding Practices and Subsequent Atopy among Children with a Family History of Asthma. Clinical \& Experimental Allergy, 37, 671-679. https://doi.org/10.1111/j.1365-2222.2007.02696.x

[12] Adriano, C. and Quintero-Romero, S. (2006) Protection, Promotion and Support of Breastfeeding in Low-Income Countries. Seminars in Fetal and Neonatal Medicine, 11, 48-53. https://doi.org/10.1016/j.siny.2005.10.007

[13] Hanif, H.M. (2013) Trends in Infant and Young Child Feeding Practices in Bangladesh, 1993-2011. International Breastfeeding Journal, 8, 10.

https://doi.org/10.1186/1746-4358-8-10

[14] Mazumder, M.S., Hossain, M.K., Islam, M.N. and Islam, K.N. (2001) Contraceptive Effectiveness of Breastfeeding and Current Contraceptive Practice in Bangladesh. Sciences, 1, 267-271. https://doi.org/10.3923/jms.2001.267.271

[15] Koenig, M.A., Fauveau, V., Chowdhury, A.I., Chakraborty, J. and Ali Khan, M. (1988) Maternal Mortality in Matlab, Bangladesh: 1976-85. Studies in Family Planning, 19, 69-80. https://doi.org/10.2307/1966492

[16] World Health Organization (2017) Regional Consultation to Protect, Promote and Support Breastfeeding with a Focus on Baby Friendly Hospital Practices. No. SEA-NUT-199. World Health Organization. Regional Office for South-East Asia.

[17] Alfredo, P., Continisio, G.I., Aldinucci, M., D’Amora, S. and Continisio, P. (2005) A Controlled Trial of the Father's Role in Breastfeeding Promotion. Pediatrics, 116, e494-e498. https://doi.org/10.1542/peds.2005-0479

[18] Biswas, L.R. (2010) Family Support on Exclusive Breastfeeding Practice among Mothers in Banglaesh. Prince of Songkla University, Songkla.

[19] Heck, K.E., Braveman, P., Cubbin, C., Chavez, G.F. and Kiely, J.L. (2006) Socioeconomic Status and Breastfeeding Initiation among California Mothers. Public Health 
Reports, 121, 51-59. https://doi.org/10.1177/003335490612100111

[20] Suzon, A., Al Mamun, A., Mahmud, N., Farzana, N., Akther Sathi, M.S., Biswas, B.K., Datta, A. and Ahmad, T. (2019) Prevalence and Associated Factors of Anemia among Pregnant Women Receiving Antenatal Care (ANC) at Fatima Hospital in Jashore, Bangladesh: A Cross-Sectional Study. Food and Nutrition Sciences, 10, 1056-1071. https://doi.org/10.4236/fns.2019.109076

[21] Rukhsana, H., Ashworth, A., Kabir, I. and Huttly, S.R.A. (2000) Effect of Community-Based Peer Counsellors on Exclusive Breastfeeding Practices in Dhaka, Bangladesh: A Randomised Controlled Trial. The Lancet, 356, 1643-1647. https://doi.org/10.1016/S0140-6736(00)03159-7

[22] BBF (2004) KAP Baseline. Bangladesh Breastfeeding Foundation, Dhaka, Bangladesh.

[23] BBF (2005) Surveillance Study on Breastfeeding and Complementary Feeding Situation \& Nutrition Status of Mothers and Children in Bangladesh. Bangladesh Breastfeeding Foundation. Dhaka, Bangladesh.

[24] BBS/UNICEF (2003) Progotir Pathey 2003 On The Road to Progress. December 2004 (Report from MICS 2003). Bangladesh Bureau of Statistics and UNICEF. Dhaka,

[25] Bangladesh BBS/UNICEF (2004) Anaemia Prevalence Survey of Urban Bangladesh and Rural Chittagong Hill Tracts 2003. Bangladesh Bureau of Statistics, Dhaka.

[26] BBS/UNICEF (2005) National Low Birth Weight Survey of Bangladesh, 2003-4. Bangladesh Bureau of Statistics, Dhaka. 